\title{
Cryoablation versus radiation therapy for low and intermediate risk localized prostate cancer: a propensity score-adjusted cohort analysis of oncologic outcomes
}

\section{Bo Chen}

Sichuan University West China Hospital

Kun Jin

Sichuan University West China Hospital

\section{Shi Qiu}

Sichuan University West China Hospital

\section{Zeyu Chen}

Sichuan University West China Hospital

Jin Li

Sichuan University West China Hospital

\section{Yin Huang}

Sichuan University West China Hospital

Tianhai Lin

Sichuan University West China Hospital

\section{Jianzhong Ai}

Sichuan University West China Hospital

liangren liu ( $\square$ liuliangren@scu.edu.cn )

Sichuan University West China Hospital https://orcid.org/0000-0001-7597-6241

\section{Qiang Wei}

Sichuan University West China Hospital

\section{Research}

Keywords: prostate cancer, cryoablation, radiation treatment, low risk, intermediate risk

Posted Date: April 15th, 2020

DOI: https://doi.org/10.21203/rs.3.rs-22734/v1

License: (9) This work is licensed under a Creative Commons Attribution 4.0 International License. Read Full License 
Page 2/15 


\section{Abstract}

Background: We are aiming to compare the oncologic outcomes between cryoablation and radiation therapy for low or intermediate risk localized prostate cancer.

Methods : Among patients diagnosed between 2004 and 2016 in SEER databases, we identified cases confirmed low or intermediate risk prostate adenocarcinoma treated with radiation treatment $(n=93041)$ or cryoablation $(n=2350)$. Propensity score matching (PSM) was performed. Kaplan-Meier method, Cox proportional hazards model were used to calculate cancer specific mortality (CSM) and overall survival (OS) in the unmatched and matched cohort, and in subgroups based on clinical characteristics.

Results: A total of 95391 patients who were diagnosed with first prostate adenocarcinoma and treated with radiation treatment $(97.54 \%)$ or cryoablation $(2.46 \%)$ were identified. In the matched cohort, cryoablation group has similar CSM (HR 1.13, 95\% Cl 0.72-1.77, P=0.6) and worse OS (HR 1.20,95\% Cl 1.04-1.39, $\mathrm{P}=0.01$ ) than radiation treatment group in the non-adjusted model as well as those in the adjusted model (HR 1.06, 95\% Cl 0.68-1.65, $\mathrm{P}=0.8$; HR 1.18, 95\% Cl 1.02-1.36, $\mathrm{P}=0.02$, respectively). For low risk disease, CSM and OS outcomes were similar between cryoablation and radiation treatment group. Last but not least, for intermediate risk patients, compared with radiation treatment group, cryoablation group has similar CSM (HR 1.26, 95\% Cl 0.90-1.77, $\mathrm{P}=0.2)$ and inferior OS (HR 1.17, 95\% $\mathrm{Cl} 1.04-1.32$, $\mathrm{P}=0.01)$.

Conclusion: In summary, for low risk disease, CSM and OS outcomes were similar between cryoablation and radiation treatment group. For intermediate risk disease, we found that radiation treatment group showed superior OS than cryoablation group.

\section{Introduction}

In the current era, prostate cancer is a commonly diagnosed malignancy in elderly men ${ }^{1}$. With increasing use of prostate specific antigen (PSA) for detection of prostate cancer, the amount of cases of prostate cancer continue to rise ${ }^{2,3}$. Furthermore, the majority of individuals are diagnosed in the local, early disease stage. Therefore, the treatment strategy of early prostate cancer is great of importance. Currently, either radical prostatectomy or radiation treatment is the gold standard of therapy of patients with localized prostate cancer ${ }^{4}$. Although both interventions have favorable long-term oncologic outcomes, due to targeting the entire prostate gland cause significant complications including incontinence, erectile dysfunction, and rectal injury et al ${ }^{5,6}$.

Taking the above negative effects of radical prostatectomy or radiotherapy into consideration, therefore, minimally invasive treatment such as cryoablation maybe the valid alternative to overtreatment and observation for localized prostate cancer with acceptable oncologic outcomes. At present, which therapy is better for localized prostate cancer is of growing interest and is worthy of further study. Furthermore, 
favorable oncologic and functional outcomes have been reported from minimal invasive therapies targeting areas of lesion rather than the entire prostate ${ }^{7-9}$.

To the best of our knowledge, multiple consensus groups have highlighted that low risk patients should not routinely be offered focal therapy and that the ideal patients are those with localized intermediate risk disease $8,10,11$. Furthermore, there are rare studies focusing on low or intermediate risk individuals received either minimally invasive therapy such as cryoablation. To address these unmet objectives, we performed the cohort study to compare the oncologic outcomes between cryoablation and radiation therapy for low or intermediate risk prostate cancer cases.

\section{Materials And Methods}

\section{Study population}

Within the Surveillance, Epidemiology and End Results program (SEER) database (18 cancer registries, accounting for $26 \%$ of the US population), we identified subjects (age at diagnosis $\geq 18$ years old) first diagnosed with prostate adenocarcinoma as the primary malignancy on the basis of anatomic site using the International Classification of Diseases for Oncology histologic types (ICD-0 code 8140) between 2004 to 2016 . According to European Association of Urology guideline ${ }^{12}$, only low or intermediate risk patients were included in this series. Furthermore, prostate adenocarcinoma was the only tumor. Individuals with death or autopsy certification were excluded from this study. The therapy strategy of patients was radiation treatment or cryoablation.

\section{Covariates}

Baseline clinical characteristics were adjusted for analyses, including age, PSA, T stage, Gleason Score, marital status, race and risk stratification.

\section{Outcomes}

The outcomes consisted of cancer specific mortality (CSM) and overall survival (OS) estimated by Kaplan Meier method.

\section{Statistical analysis}

For baseline clinical characteristics, categorical variables are presented in terms of frequency with its proportion. Statistical difference between proportions of the two groups (cryoablation vs. radiation treatment) was determined by Chi-square test. CSM and OS were compared of two groups by using the unadjusted Kaplan Meier curves with the log-rank test followed by Cox regression models adjusting for several demographic and tumor characteristics.

Subgroup analyses were performed by stratifying patients by age, T stage, PSA, Gleason Score and risk stratification. To confirm the results, we performed a secondary analysis using propensity score matching (PSM) since two groups differed significantly in some of the baseline characteristics. 
Propensity scores were estimated in multivariable logistic regression models, where the dependent variables was the treatment (cryoablation vs. radiation treatment). The independent variables (age, PSA, T stage, Gleason Score, race and risk stratification) were performed in the PSM analysis. The greedy matching method within specified caliper distances was applied to match patients in two groups with the matching ratio of 1:6 using a caliper equal to $0.05^{13}$. Inverse probability of treatment weighing (IPTW) and standardized mortality ratio weighting (SMRW) calculated with the propensity score to estimate the relationship between treatment types and outcomes among the entire cohort.

All the analyses were performed with the statistical software packages R (http://www.R-project.org, The R Foundation) and EmpowerStats (http://www.empowerstats.com, X\&Y Solutions, Inc., Boston, MA). P< 0.05 was considered statistically significant.

\section{Results}

\section{Baseline clinical characteristics}

The baseline clinical characteristics were summarized in Table 1. A total of 95391 patients who were diagnosed with first prostate adenocarcinoma and treated with radiation treatment $(97.54 \%)$ or cryoablation (2.46\%) were identified. In the unmatched cohort, compared with patients underwent radiation treatment, those underwent cryoablation were older $(P<0.001)$, more likely to be white $(P=$ 0.004), with low PSA $(P<0.001)$, high T stage $(P<0.001)$, high Gleason score $(G S)(P<0.001)$ and intermediate risk $(P<0.001)$. 
Table 1

Baseline characteristics of unmatched cohort and matched cohort.

\begin{tabular}{|c|c|c|c|c|c|c|}
\hline \multirow[t]{2}{*}{ Characteristics } & \multicolumn{3}{|c|}{ Before matching } & \multicolumn{3}{|c|}{ After matching } \\
\hline & $\begin{array}{l}\text { RT } \\
\mathrm{n}=93041\end{array}$ & $\begin{array}{l}\text { cryoablation } \\
n=2350\end{array}$ & $\begin{array}{l}\text { P- } \\
\text { value }\end{array}$ & $\begin{array}{l}\text { RT } \\
n=14100\end{array}$ & $\begin{array}{l}\text { cryoablation } \\
n=2350\end{array}$ & $\begin{array}{l}\mathrm{P} \text { - } \\
\text { value }\end{array}$ \\
\hline Age (years) & $\begin{array}{l}66.66 \pm \\
7.73\end{array}$ & $68.91 \pm 7.55$ & $\begin{array}{l}< \\
0.001\end{array}$ & $\begin{array}{l}68.97 \pm \\
7.56\end{array}$ & $68.91 \pm 7.55$ & 0.7 \\
\hline PSA (ng/ml) & $7.05 \pm 3.41$ & $6.72 \pm 3.35$ & $<.001$ & $\begin{array}{l}6.83 \pm \\
3.30\end{array}$ & $6.72 \pm 3.35$ & 0.1 \\
\hline T stage & & & $\begin{array}{l}< \\
0.001\end{array}$ & & & 0.5 \\
\hline $\mathrm{T} 1$ & $\begin{array}{l}82281 \\
(88.44 \%)\end{array}$ & $\begin{array}{l}1993 \\
(84.81 \%)\end{array}$ & & $\begin{array}{l}11855 \\
(84.1 \%)\end{array}$ & $\begin{array}{l}1993 \\
(84.8 \%)\end{array}$ & \\
\hline T2a & $\begin{array}{l}7784 \\
(8.37 \%)\end{array}$ & $\begin{array}{l}242 \\
(10.30 \%)\end{array}$ & & $\begin{array}{l}1569 \\
(11.1 \%)\end{array}$ & $242(10.3 \%)$ & \\
\hline $\mathrm{T} 2 \mathrm{~b}$ & $\begin{array}{l}2976 \\
(3.20 \%)\end{array}$ & $115(4.89 \%)$ & & $\begin{array}{l}676 \\
(4.8 \%)\end{array}$ & $115(4.9 \%)$ & 0.4 \\
\hline GS & & & $<.001$ & & & 0.7 \\
\hline $3+3$ & $\begin{array}{l}50100 \\
(53.85 \%)\end{array}$ & $\begin{array}{l}1135 \\
(48.30 \%)\end{array}$ & & $\begin{array}{l}6709 \\
(47.6 \%)\end{array}$ & $\begin{array}{l}1135 \\
(48.3 \%)\end{array}$ & \\
\hline $3+4$ & $\begin{array}{l}29796 \\
(32.02 \%)\end{array}$ & $\begin{array}{l}827 \\
(35.19 \%)\end{array}$ & & $\begin{array}{l}4960 \\
(35.2 \%)\end{array}$ & $827(35.2 \%)$ & \\
\hline $4+3$ & $\begin{array}{l}13145 \\
(14.13 \%)\end{array}$ & $\begin{array}{l}388 \\
(16.51 \%)\end{array}$ & & $\begin{array}{l}2431 \\
(17.2 \%)\end{array}$ & 388 (16.5\%) & \\
\hline Marital status & & & 0.07 & & & 0.1 \\
\hline Married & $\begin{array}{l}64723 \\
(69.56 \%)\end{array}$ & $\begin{array}{l}1658 \\
(70.55 \%)\end{array}$ & & $\begin{array}{l}9929 \\
(70.4 \%)\end{array}$ & $\begin{array}{l}1658 \\
(70.6 \%)\end{array}$ & \\
\hline Single & $\begin{array}{l}9793 \\
(10.53 \%)\end{array}$ & $220(9.36 \%)$ & & $\begin{array}{l}1337 \\
(9.5 \%)\end{array}$ & $220(9.4 \%)$ & \\
\hline Divorced/Widowed & $\begin{array}{l}10861 \\
(11.67 \%)\end{array}$ & $\begin{array}{l}256 \\
(10.89 \%)\end{array}$ & & $\begin{array}{l}1702 \\
(12.1 \%)\end{array}$ & $256(10.9 \%)$ & \\
\hline Unknown & $\begin{array}{l}7664 \\
(8.24 \%)\end{array}$ & $216(9.19 \%)$ & & $1132(8 \%)$ & $216(9.2 \%)$ & \\
\hline Race & & & 0.004 & & & 0.3 \\
\hline
\end{tabular}

$\mathrm{RT}$ = radiation treatment; PSA = prostate specific antigen; GS = Gleason Score 


\begin{tabular}{|c|c|c|c|c|c|c|}
\hline \multirow[t]{2}{*}{ Characteristics } & \multicolumn{3}{|c|}{ Before matching } & \multicolumn{3}{|c|}{ After matching } \\
\hline & $\begin{array}{l}\text { RT } \\
n=93041\end{array}$ & $\begin{array}{l}\text { cryoablation } \\
n=2350\end{array}$ & $\begin{array}{l}\mathrm{P} \text { - } \\
\text { value }\end{array}$ & $\begin{array}{l}\text { RT } \\
n=14100\end{array}$ & $\begin{array}{l}\text { cryoablation } \\
n=2350\end{array}$ & $\begin{array}{l}P \text { - } \\
\text { value }\end{array}$ \\
\hline White & $\begin{array}{l}70481 \\
(75.75 \%)\end{array}$ & $\begin{array}{l}1857 \\
(79.02 \%)\end{array}$ & & $\begin{array}{l}10896 \\
(77.3 \%)\end{array}$ & $1857(79 \%)$ & \\
\hline Black & $\begin{array}{l}16764 \\
(18.02 \%)\end{array}$ & $\begin{array}{l}370 \\
(15.74 \%)\end{array}$ & & $\begin{array}{l}2336 \\
(16.6 \%)\end{array}$ & $370(15.7 \%)$ & \\
\hline Other & $\begin{array}{l}4537 \\
(4.88 \%)\end{array}$ & $97(4.13 \%)$ & & $\begin{array}{l}682 \\
(4.8 \%)\end{array}$ & $97(4.1 \%)$ & \\
\hline Unkown & $\begin{array}{l}1259 \\
(1.35 \%)\end{array}$ & $26(1.11 \%)$ & & $\begin{array}{l}186 \\
(1.3 \%)\end{array}$ & $26(1.1 \%)$ & \\
\hline Risk stratification & & & $\begin{array}{l}<.001 \\
0.00\end{array}$ & & & 0.5 \\
\hline Low risk & $\begin{array}{l}42597 \\
(45.78 \%)\end{array}$ & $\begin{array}{l}967 \\
(41.15 \%)\end{array}$ & & $\begin{array}{l}5684 \\
(40.3 \%)\end{array}$ & $967(41.1 \%)$ & \\
\hline Intermediate risk & $\begin{array}{l}50444 \\
(54.22 \%)\end{array}$ & $\begin{array}{l}1383 \\
(58.85 \%)\end{array}$ & & $\begin{array}{l}8416 \\
(59.7 \%)\end{array}$ & $\begin{array}{l}1383 \\
(58.9 \%)\end{array}$ & \\
\hline
\end{tabular}

\section{Unmatched cohort}

Kaplan-Meier survival curves for CSM and OS are presented in Fig. 1. Results showed that CSM was similar between radiation treatment and cryoablation group $(P=0.17)$ (Fig. 1a). Furthermore, the radiation treatment group has a better OS than cryoablation group $(P<0.0001)$ (Fig. 1b). In the unmatched cohort, compared with radiation treatment group, Cox proportional hazards model manifested that cryoablation group has similar CSM (HR 1.24, 95\% Cl 0.91-1.69, $\mathrm{P}=0.2)$ and worse OS (HR 1.37, 95\% Cl 1.25-1.51, $\mathrm{P}<$ $0.00001)$ in the non-adjusted model, which was supported by the adjust model (HR $1.09,95 \% \mathrm{Cl} 0.80-$ $1.48, \mathrm{P}=0.6 ; \mathrm{HR} 1.18,95 \% \mathrm{Cl} 1.07-1.30, \mathrm{P}=0.0008$, respectively) (Table 2). 
Table 2

Comparison of CSM or OS between cryoablation vs. RT in the unmatched cohort.

\begin{tabular}{|c|c|c|c|c|}
\hline \multirow[t]{2}{*}{ Exposure } & \multicolumn{2}{|c|}{ Non-adjusted } & \multicolumn{2}{|l|}{ Adjust } \\
\hline & $\mathrm{HR}(95 \% \mathrm{Cl})$ & $P$ value & $\mathrm{HR}(95 \% \mathrm{Cl})$ & $P$ value \\
\hline \multicolumn{5}{|l|}{ CSM } \\
\hline RT & 1 & & 1 & \\
\hline cryoablation & $\begin{array}{l}1.24 \\
(0.91,1.69)\end{array}$ & 0.2 & $\begin{array}{l}1.09 \\
(0.80,1.48)\end{array}$ & 0.6 \\
\hline \multicolumn{5}{|l|}{ os } \\
\hline RT & 1 & & 1 & \\
\hline cryoablation & $\begin{array}{l}1.37 \\
(1.25,1.51)\end{array}$ & $<0.00001$ & $\begin{array}{l}1.18 \\
(1.07,1.30)\end{array}$ & 0.0008 \\
\hline \multicolumn{5}{|c|}{$\begin{array}{l}\mathrm{CSM}=\text { cancer-specific mortality; OS = overall survival; } \mathrm{RT}=\text { radiation treatment; } \mathrm{HR}=\text { hazard ratio, } \mathrm{Cl}= \\
\text { confidence intervals }\end{array}$} \\
\hline \multicolumn{5}{|c|}{${ }^{*} \mathrm{P}<0.05 ; * \star \mathrm{P}<0.01 ; * \star \star \mathrm{P}<0.001 ; * \star \star \star \mathrm{P}<0.0001$} \\
\hline \multicolumn{5}{|c|}{ Non-adjusted model adjust for: None } \\
\hline \multicolumn{5}{|c|}{ Adjust model adjust for: Age; T stage; PSA; GS } \\
\hline
\end{tabular}

In exploratory subgroup analyses, Cox proportional hazards model showed that CSM and OS were similar between radiation treatment group and cryoablation group for quartile 1(Q1) and quartile 3 (Q3) of age. Nevertheless, for quartile 2 (Q2) of age, cryoablation group has similar CSM (HR 1.38, 95\% Cl, 0.68-2.78, $\mathrm{P}=0.4)$ and worse $\mathrm{OS}(\mathrm{HR} 1.60,95 \% \mathrm{Cl} 1.27-2.01, \mathrm{P} \otimes 0.0001)$ than radiation treatment group as well as quartile 4 (Q4) of age (HR 1.19, 95\% Cl 0.79-1.79, $\mathrm{P}=0.4 ; \mathrm{HR}=1.18,95 \% \mathrm{Cl} 1.04-1.34, \mathrm{P}=0.01$, respectively). Then, compared with radiation treatment group, cryoablation group has similar CSM and inferior OS (HR 1.12, 95\% Cl 0.81-1.56, $\mathrm{P}=0.5 ; \mathrm{HR} 1.16,95 \% \mathrm{Cl} 1.04-1.28, \mathrm{P}=0.007$, respectively). Nevertheless, CSM and OS were similar between radiation treatment and cryoablation group for T2a and T2b patients. In addition, for patients with PSA (4-10 ng/ml), Cox regression showed that cryoablation group has similar CSM (HR 1.00, 95\% Cl, 0.68-1.46, P = 0.9) and worse OS (HR 1.18, 95\% Cl 1.05-1.32, P $=0.005$ ) than radiation treatment group. For patients with $\mathrm{GS}=3+3$, cryoablation group has worse OS than radiation treatment group (HR 1.16, 95\% Cl 1.00-1.34, $\mathrm{P}=0.04$ ). For patients with $\mathrm{GS}=4+3$, compared with radiation treatment group, cryoablation group has higher CSM (HR 1.64, 95\% Cl 1.00-2.67, $\mathrm{P}=0.04)$ and inferior OS (HR 1.33, 95\% Cl 1.08-1.63, $\mathrm{P}=0.007)$. Furthermore, for low risk patients, CSM and $\mathrm{OS}$ outcomes were similar between cryoablation and radiation treatment group. Last but not least, 
for intermediate risk patients, compared with radiation treatment group, cryoablation group has similar CSM (HR 1.26, 95\% Cl 0.90-1.77, $\mathrm{P}=0.2)$ and inferior OS (HR 1.17, 95\% Cl 1.04-1.32, $\mathrm{P}=0.01)$ (Fig. 2).

\section{Propensity-score matched cohort}

The propensity score-matched cohort included 14100 patients in radiation treatment group and 2350 patients in cryoablation group. After propensity score balancing, covariate balance was achieved for all included variables (Table 1). In the matched group, cryoablation group has similar CSM (HR $1.13,95 \% \mathrm{Cl}$ $0.72-1.77, \mathrm{P}=0.6)$ and worse $\mathrm{OS}(\mathrm{HR} 1.20,95 \% \mathrm{Cl} 1.04-1.39, \mathrm{P}=0.01)$ than radiation treatment group in the non-adjusted model as well as those in the adjusted model (HR 1.06, 95\% $\mathrm{Cl} 0.68-1.65, \mathrm{P}=0.8 ; \mathrm{HR}$ $1.18,95 \% \mathrm{Cl} 1.02-1.36, \mathrm{P}=0.02$, respectively) (Table 3 ).

Table 3

Comparison of CSM or OS between cryoablation vs. RT in the matched cohort.

\begin{tabular}{|lllll|}
\hline Exposure & Non-adjusted & & Adjust & \\
\hline & HR(95\%Cl) & P value & HR $(95 \% \mathrm{Cl})$ & P value \\
\hline CSM & & & \\
RT & 1 & & 1 & \\
\hline cryoablation & 1.13 & 0.6 & 1.06 & 0.8 \\
OS & $(0.72,1.77)$ & & $(0.68,1.65)$ & \\
RT & & & \\
cryoablation & 1 & & 1 & 0.02 \\
& 1.20 & 0.01 & 1.18 & \\
\hline
\end{tabular}

$\mathrm{CSM}=$ cancer-specific mortality; $\mathrm{OS}=$ overall survival; $\mathrm{RT}$ = radiation treatment; $\mathrm{HR}$ = hazard ratio, $\mathrm{Cl}=$ confidence intervals

* $\mathrm{P}<0.05 ; \star \star \mathrm{P}<0.01 ; * \star \star \mathrm{P}<0.001 ; * \star \star \star \mathrm{P}<0.0001$

Non-adjusted model adjust for: None

Adjust model adjust for: Age; T stage; PSA; GS

HR: represents the association of cryoablation versus RT with outcomes. HR囚1 indicates an increased risk of outcome in patients receiving cryoablation.

\section{Sensitivity analysis}

In IPTW and SMRW model, cryoablation is associated with inferior OS (IPTW: HR 1.20, 95\% Cl 1.17-1.22, $\mathrm{P}<0.00001$; SMRW: HR 1.18, 95\%Cl 1.02-1.36, $\mathrm{P}=0.02$ ) in Cox proportional hazards model adjusted for age, T stage, PSA and GS. In IPTW model, furthermore, cryoablation is associated with inferior CSM (HR 
$1.09,95 \% \mathrm{Cl} 1.01-1.17, \mathrm{P}=0.02)$ in Cox proportional hazards model adjusted for age, $\mathrm{T}$ stage, $\mathrm{PSA}$ and GS. Nevertheless, in SMRW model, cryoablation group has similar CSM (HR 1.06, 95\% Cl 0.68-1.65, P = 0.8 ) than radiation treatment group in Cox proportional hazards model adjusted for age, T stage, PSA and GS (Table S1).

\section{Discussion}

Previously studies had demonstrated that cryoablation is an effective treatment and minimally invasive, with low surgical risk, low morbidity, with good results in the long follow-up in terms of survival, biochemical recurrence, CSM and OS, for low risk patients ${ }^{14}$. Nevertheless, the consensuses that low risk patients should not routinely be offered focal therapy and the ideal patients receiving cryoablation are those with intermediate risk disease have been highlighted $8,10,11$. Furthermore, another series revealed that cryoablation for intermediate results in good rates of cancer control and low rates of treatment related side effects ${ }^{4}$. In this study, therefore, we report the CSM and OS outcomes in patients with low or intermediate risk.

In this retrospective cohort of prostate adenocarcinoma with low or intermediate risk, firstly, we found that cryoablation and radiation treatment are equal for all patients in terms of CSM. Nevertheless, results manifested that radiation treatment group has a better OS than cryoablation group.

A meta-analysis showed that five-year biochemical recurrence of salvage cryoablation is similar to salvage radiotherapy for high risk and locally recurrent prostate cancer. Nevertheless, for high risk prostate cancer, cryoablation showed an advantage than radiation treatment ${ }^{15}$. Then, another study found that focal cryoablation in patients with clinically unilateral, low-intermediate-risk prostate cancer appears favorable, and the side-effect profile is low ${ }^{16}$. In addition, Durand $\mathrm{M}$ et al. ${ }^{17}$ manifested that cryoablation is a low-morbidity option in patients with low-risk diasease. Our results showed that cryoablation is similar to radiation treatment in terms of CSM and OS for low risk patients. Nevertheless, we found that radiation treatment group has superior OS than cryoablation group for intermediate risk patients.

To the best of our knowledge, this is the first study that uses SEER database to compare cryoablation with radiation treatment for low or intermediate risk patients. In order to explain our findings, we explored survival benefit in each subgroup stratified by baseline characteristics. Although the radiation treatment group were younger, and more likely to be with early stage, low GS and low risk, we adjusted for baseline characteristics which could potentially bias the comparison in Cox proportional hazards model and competing risk model to confirm the robustness of our findings.

This study is not without limitations. Firstly, it is the retrospective nature of this study. Secondly, the SEER database does not provide information on several variables that could be of interest and value such as biochemical recurrence as well as recurrence free survival would add to the quality of the analyses. 
Given the retrospective nature of our study, the results were interpreted with caution. Further prospective studies are needed to investigate the optimal risk stratification for choosing which therapy to perform. Maybe randomized clinical trial would perform subgroup analysis of risk stratification and minimize selection bias of patients' dispositions like comorbidities and tumor complexity.

\section{Conclusion}

In summary, for low or intermediate risk disease, cryoablation group showed similar CSM and inferior OS than radiation treatment group. Furthermore, for low risk disease, CSM and OS outcomes were similar between cryoablation and radiation treatment group. For intermediate risk disease, we found that radiation treatment group showed superior OS than cryoablation group.

\section{Abbreviations}

PSM, propensity score matching; CSM, cancer specific mortality; OS, overall survival; PSA, prostate specific antigen; IPTW, inverse probability of treatment weighing; SMRW, standardized mortality ratio weighting; RT, radiation treatment; $\mathrm{HR}$, hazard ratio; $\mathrm{Cl}$, confidence intervals; SEER, Surveillance, Epidemiology and End Results program.

\section{Declarations}

\section{Acknowledgements}

Not applicable.

\section{Author Contributions}

Liangren Liu and Qiang Wei designed this study. Zeyu Chen, Jin Li, Yin Huang, Tianhai Lin and Jianzhong Ai collected the data. Bo Chen, Kun Jin and Shi Qiu analyzed the data and written the manuscript. All the authors revised and final approved the manuscript.

\section{Funding}

This research was supported by the National Natural Science Foundation of China (Grant no. 81370855区 81770756, 81702536 and 81200551) and Project of Sichuan Province Science and Technology Department (Grant no. 2015 SZ0230 and 2017KJT0034).

\section{Ethics approval and consent to participate}

Not applicable.

\section{Consent for publication}

Not applicable. 


\section{Competing interests}

The authors declare that they have no competing interest.

\section{References}

1. Siegel RL, Miller KD, Jemal A. Cancer statistics, 2019. CA Cancer J Clin. 2019;69(1):7-34.

2. Global Burden of Disease Cancer Collaboration. Fitzmaurice C, Akinyemiju TF, Al Lami FH, Alam T, Alizadeh-Navaei R, Allen C, Alsharif U, Alvis-Guzman N, Amini E, Anderson BO, Aremu O, et al. Global, Regional, and National Cancer Incidence, Mortality, Years of Life Lost, Years Lived With Disability, and Disability-Adjusted Life-Years for 29 Cancer Groups, 1990 to 2016: A Systematic Analysis for the Global Burden of Disease Study. JAMA Oncol 2018;4(11):1553-68.

3. Siegel RL, Miller KD, Jemal A. Cancer statistics, 2020. CA Cancer J Clin. 2020;70(1):7-30.

4. Shah TT, Peters M, Eldred-Evans D, Miah S, Yap T, Faure-Walker NA, Hosking-Jervis F, Thomas B, Dudderidge T, Hindley RG, McCracken S, Greene D, et al. Early-Medium-Term Outcomes of Primary Focal Cryotherapy to Treat Nonmetastatic Clinically Significant Prostate Cancer from a Prospective Multicentre Registry. Eur Urol. 2019;76(1):98-105.

5. Menon M, Dalela D, Jamil M, Diaz M, Tallman C, Abdollah F, Sood A, Lehtola L, Miller D, Jeong W. Functional Recovery, Oncologic Outcomes and Postoperative Complications after Robot-Assisted Radical Prostatectomy: An Evidence-Based Analysis Comparing the Retzius Sparing and Standard Approaches. J Urol. 2018;199(5):1210-7.

6. Hamdy FC, Donovan JL, Lane JA, Mason M, Metcalfe C, Holding P, Davis M, Peters TJ, Turner EL, Martin RM, Oxley J, Robinson M, et al. 10-Year Outcomes after Monitoring, Surgery, or Radiotherapy for Localized Prostate Cancer. N Engl J Med. 2016;375(15):1415-24.

7. Ahmed HU, Pendse D, Illing R, Allen C, van der Meulen JH, Emberton M. Will focal therapy become a standard of care for men with localized prostate cancer. Nat Clin Pract Oncol. 2007;4(11):632-42.

8. Valerio M, Cerantola Y, Eggener SE, Lepor H, Polascik TJ, Villers A, Emberton M. New and Established Technology in Focal Ablation of the Prostate: A Systematic Review. Eur Urol. 2017;71(1):17-34.

9. Shah TT, Ahmed H, Kanthabalan A, Lau B, Ghei M, Maraj B, Arya M. Focal cryotherapy of localized prostate cancer: a systematic review of the literature. Expert Rev Anticancer Ther. 2014;14(11):133747.

10. van den Bos W, Muller BG, Ahmed H, Bangma CH, Barret E, Crouzet S, Eggener SE, Gill IS, Joniau S, Kovacs G, Pahernik S, de la Rosette JJ, et al. Focal therapy in prostate cancer: international multidisciplinary consensus on trial design. Eur Urol. 2014;65(6):1078-83.

11. Tay KJ, Scheltema MJ, Ahmed HU, Barret E, Coleman JA, Dominguez-Escrig J, Ghai S, Huang J, Jones JS, Klotz LH, Robertson CN, Sanchez-Salas R, et al. Patient selection for prostate focal therapy in the era of active surveillance: an International Delphi Consensus Project. Prostate Cancer Prostatic Dis. 2017;20(3):294-9. 
12. Lam T, MacLennan S, Willemse PM, Mason MD, Plass K, Shepherd R, Baanders R, Bangma CH, Bjartell A, Bossi A, Briers E, Briganti A, et al. EAU-EANM-ESTRO-ESUR-SIOG Prostate Cancer Guideline Panel Consensus Statements for Deferred Treatment with Curative Intent for Localised Prostate Cancer from an International Collaborative Study (DETECTIVE Study). Eur Urol. 2019;76(6):790-813.

13. Robins JM, Hernán MA, Brumback B. Marginal structural models and causal inference in epidemiology. Epidemiology. 2000;11(5):550-60.

14. Chinenov DV, Rapoport LM, Shpot EV, Enikeev DV, Chernov YN, Taratkin MS, Korolev DO. Comparative results of cryoablation and laparoscopic radical prostatectomy in the treatment of localized prostate cancer. Urologia. 2018;85(2):68-72.

15. Liang $X$, Yang XL, Guo Z. [Effect on cryoablation of high-risk and locally recurrent prostate cancer: a Meta-analysis]. Zhonghua Yi Xue Za Zhi. 2017;97(25):1975-80.

16. Lian H, Zhuang J, Yang R, Qu F, Wang W, Lin T, Guo H. Focal cryoablation for unilateral lowintermediate-risk prostate cancer: 63-month mean follow-up results of 41 patients. Int Urol Nephrol. 2016;48(1):85-90.

17. Durand M, Barret E, Galiano M, Rozet F, Sanchez-Salas R, Ahallal Y, Macek P, Gaya JM, Cerruti J, Devilliers $\mathrm{H}$, Loeffler $\mathrm{J}$, Amiel J, et al. Focal cryoablation: a treatment option for unilateral low-risk prostate cancer. BJU Int. 2014;113(1):56-64.

\section{Figures}
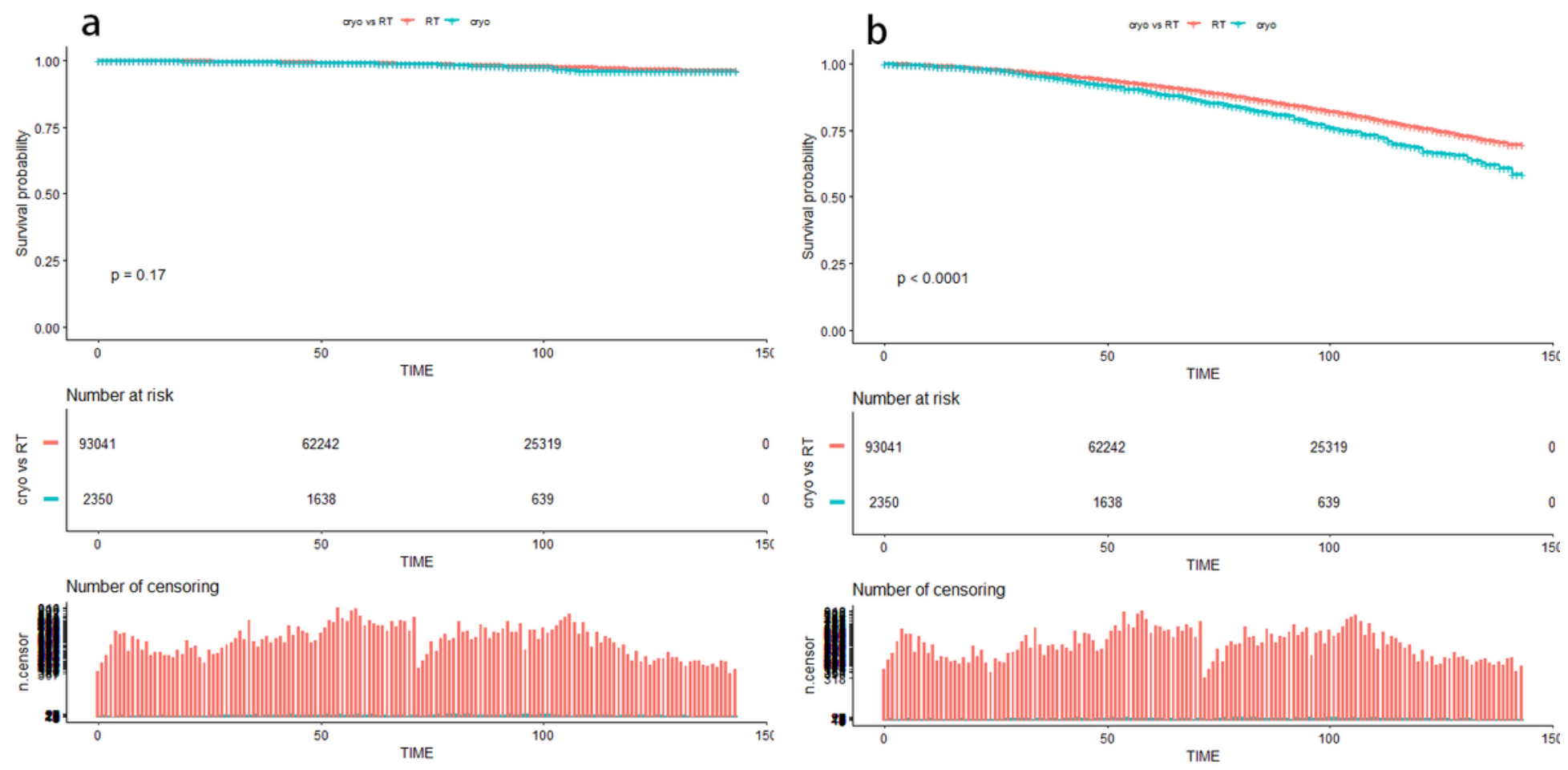

Figure 1 
CSM (a) and OS (b) between cryoablation and radiation treatment in the unmatched cohort. cryo=cryoablation.

\section{a}

\section{Age}

Q1

Q2

Q3

Q4

T stage

T1

T2a

T2b

PSA

$<4$

4-10

$=10$

GS

$3+3$

$3+4$

$4+3$

low vs intermediate low

intermediate

\section{b}

Age

Q1

Q2

Q3

Q4

$\mathrm{T}$ stage

T1

T2a

$\mathrm{T} 2 \mathrm{~b}$

PSA

$<4$

4-10

210

GS

$3+3$

$3+4$

$4+3$

low vs intermediate

low

intermediate
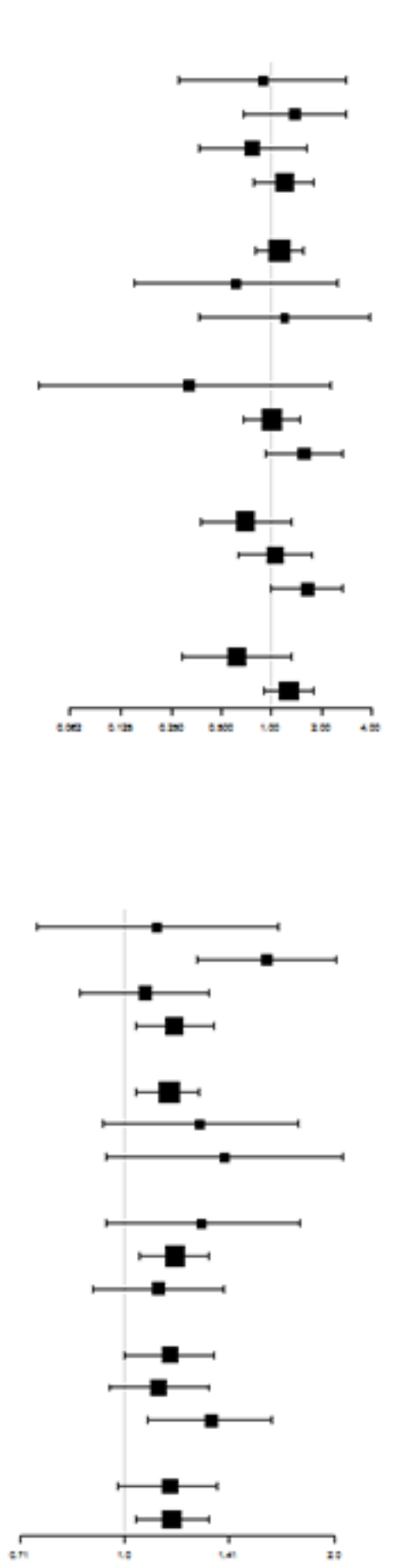

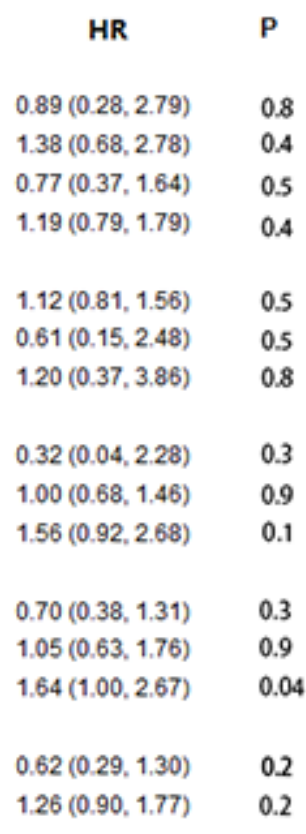

$\begin{array}{cc}\text { HR } & \text { P } \\ & \\ 1.11(0.75,1.66) & 0.6 \\ 1.60(1.27,2.01) & <0.0001 \\ 1.07(0.86,1.32) & 0.6 \\ 1.18(1.04,1.34) & 0.01 \\ & \\ 1.16(1.04,1.28) & 0.007 \\ 1.28(0.93,1.77) & 0.1 \\ 1.39(0.94,2.06) & 0.1 \\ & \\ 1.29(0.94,1.78) & 0.1 \\ 1.18(1.05,1.32) & 0.005 \\ 1.12(0.90,1.39) & 0.3 \\ & \\ 1.16(1.00,1.34) & 0.04 \\ 1.12(0.95,1.32) & 0.2 \\ 1.33(1.08,1.63) & 0.007 \\ 1.16(0.98,1.36) & 0.08 \\ 1.17(1.04,1.32) & 0.01 \\ & \end{array}$

\section{Figure 3}

Subgroup analysis of CSM (a) and OS (b) between cryoablation and radiation treatment in the unmatched cohort stratified by baseline characteristics in the unmatched cohort.

\section{Supplementary Files}


This is a list of supplementary files associated with this preprint. Click to download.

- TableS1sensitivityanalysis.docx

- TableS1sensitivityanalysis.docx

- TableS1sensitivityanalysis.docx 